\title{
O significado do Projeto Político Pedagógico na construção de ações e relações participativas na educação do campo
}

\author{
Edson Caetano ${ }^{1 \mathrm{ii}}$, Iorim Rodrigues da Silva ${ }^{2}$ \\ ${ }^{1}$ Universidade Federal de Mato Grosso - UFMT. Departamento de Teoria e Fundamentos da Educação/Instituto \\ de Educação. Avenida Fernando Corrêa da Costa, no 2367, Boa Esperança. Cuiabá - MT. \\ Brasil. caetanoedson@ hotmail.com. ${ }^{2}$ Escola Municipal Rural Fazenda Carimã.
}

RESUMO. Analisamos, neste artigo, a compreensão que seis professores de uma escola do campo expressam sobre o significado do Projeto Político Pedagógico enquanto instrumento de construção de ações e relações participativas, portanto, democráticas. Este artigo é resultado de um estudo bibliográfico e investigativo que tem como foco o significado do Projeto Político Pedagógico como instrumento fundante na construção da democratização da gestão escolar. Assim, o objetivo foi analisar a compreensão que os professores apresentam sobre o significado do Projeto Político Pedagógico de modo a contemplar, ou não, os dois princípios básicos de uma gestão democrática: a autonomia e a participação. Nesse sentido a escola pública tem o desafio de responder às demandas que os contextos lhe colocam, na perspectiva de construção de uma sociedade mais igualitária, em que os sujeitos possam participar como atores e não apenas como espectadores ou sujeitos de validação das decisões previamente tomadas pela equipe diretiva da escola.

Palavras-chave: Gestão Democrática, Escola do Campo, Projeto Político Pedagógico, Participação, Autonomia. 


\title{
The meaning of the Pedagogical Political Project in the construction of participatory actions and relationships in rural education
}

\begin{abstract}
We analyze in this article the understanding that six teachers of a rural school expresses about the meaning of the Pedagogical Political Project as an instrument for the construction of participatory actions and relations, therefore, democratic. This article is the result of a bibliographical and investigative study that focuses on the meaning of the Pedagogical Political Project as a founding instrument in the construction of the democratization of school management. Thus, the objective was to analyze teachers' understanding of the meaning of the Political Pedagogical Project in order to contemplate or not the two basic principles of democratic management: autonomy and participation. In this sense, the public school has the challenge of responding to the demands that the contexts place on it, in the perspective of building a more egalitarian society, in which the subjects can participate as actors and not only as spectators or subjects of validation of the decisions previously taken by the Team of the school.
\end{abstract}

Keywords: Democratic Management, Rural School, Political Educational Project, Participation, Autonomy 


\title{
El significado del Proyecto Político Pedagógico en la construcción de acciones y relaciones participativas en la educación del campo
}

\begin{abstract}
RESUMEN. En este artículo, analizamos en la comprensión que seis profesores de una escuela del campo expresan sobre el significado del Proyecto Político Pedagógico como instrumento de construcción de acciones y relaciones participativas, por lo tanto, democráticas. Este artículo es el resultado de un estudio bibliográfico e investigativo que tiene como foco el significado del Proyecto Político Pedagógico como instrumento fundante en la construcción de la democratización de la gestión escolar. Así, el objetivo fue analizar la comprensión que los profesores presentan sobre el significado del Proyecto Político Pedagógico para contemplar, o no, los dos principios básicos de una gestión democrática: la autonomía y la participación. En ese sentido la escuela pública tiene el desafío de responder a las demandas que los contextos le plantean, en la perspectiva de la construcción de una sociedad más igualitaria, en que los sujetos puedan participar como actores y no sólo como espectadores o sujetos de validación de las decisiones previamente tomadas por la sociedad Equipo directivo de la escuela.
\end{abstract}

Palabras clave: Gestión Democrática, Escuela de Campo, Proyecto Político Pedagógico, Participación, Autonomía. 


\section{Introdução}

Este artigo tem como objeto de discussão a gestão escolar na educação do campo com ênfase no significado do Projeto Político Pedagógico como instrumento de democratização da gestão. Nesse sentido, buscou-se analisar a compreensão que os professores apresentam sobre o significado do processo de elaboração do Projeto Político Pedagógico como condição de construção de ações e relações participativas no interior da escola.

Pensar o processo de democratização da escola, nesse sentido, requer repensar a sua organização e gestão, o que implica na consolidação de mecanismos de construção da participação, como a eleição para escolha dos gestores, a consolidação dos Conselhos Deliberativos Escolares e a construção coletiva do Projeto Político Pedagógico, elementos que compõem a gestão democrática, como princípio estabelecido na Constituição Federal de 1988, na Lei de Diretrizes e Bases da Educação Nacional de 1996 e nas Diretrizes Operacionais para a Educação Básica das Escolas do Campo de 2002.

Construir uma nova lógica de gestão, que conte com a participação da comunidade e dos atores diretamente envolvidos com a escola, implica rever o modelo adotado pelos sistemas públicos, cuja estruturação e funcionamento vivem até hoje características de um modelo centralizador. Essa perspectiva implica em redesenhar o horizonte político da gestão democrática como princípio de luta em prol da efetiva autonomia, compreendida como capacidade de cada povo de autogovernar- se, de reivindicar para si a responsabilidade das tomadas de decisão naquilo que diz respeito à própria escola.

Com a realização da pesquisa, constatou-se que os professores percebem a importância do Projeto Político Pedagógico para a democratização da gestão, mas há ausência da consolidação de práticas de participação efetiva dos atores da comunidade escolar de maneira a que contribuam significativamente para a autonomia e para a consolidação da gestão mais democrática. Assim, é essencial que se repense o papel desempenhado pela escola e que o Projeto Político Pedagógico constitua-se, na prática, como instrumento que possa fortalecer a gestão escolar, consolidando sua democratização com a participação de todos os sujeitos envolvidos no processo educacional.

\section{Cenário da pesquisa}

A pesquisa ${ }^{\text {iii }}$ foi realizada em uma escola do campo da rede municipal de ensino do município de Rondonópolis, 
estado de Mato Grosso, que entende que a sua organização configura-se nos princípios da gestão democrática. A criação desta escola na região é fruto da luta efetuada pelos trabalhadores e trabalhadoras rurais ali residentes, em decorrência disso, a escola nasceu tomando posição contra a lógica econômica que expropria as famílias de trabalhadores de suas terras. A história da luta desses trabalhadores começa pelo ano de 1993, quando o "Grupo Itiratupã", liderado por "Gerônimo sem terra" pretendia a área da Fazenda Itiratupã. Naquela época o movimento não era muito organizado, as terras eram apropriadas e os apropriadores expulsos pela polícia ou pelos fazendeiros.

O "Grupo Itiratupã" dividiu-se e formou o grupo "A terra é nossa", liderado por Wilson Martins. Esse grupo se organizou de forma diferente, não mais se apropriando das terras, sendo que em 19 de outubro de 1996 foram assentados na Fazenda Carimã. Assim, no mês de fevereiro de 1997, os filhos dos assentados começaram a estudar em salas improvisadas e anexas à Escola Municipal Rural Nossa Senhora Aparecida II. A luta por melhores condições de vida continuou, sendo que e a escola era uma das prioridades. Com o sonho realizado, nas palavras de Wilson Martins:
Por ser fonte de conhecimento onde nossos filhos aprenderão; e em homenagem ao nome da fazenda onde nos assentamos e onde poderemos ter uma vida digna e condições de sobreviver daquilo que produzirmos na terra, não poderíamos dar outro nome à escola a não ser Escola Municipal Rural Fazenda Carimã. (Documentos da Secretaria Municipal de Educação de Rondonópolis, 2000, p. 3).

Em se tratando do desenvolvimento da pesquisa empírica propriamente dita, foi utilizado o questionário como instrumento de coleta de dados. Não houve delimitação de espaço para a observação, ela aconteceu simultaneamente às entrevistas, por meio de um olhar atento sobre os entrevistados com a finalidade de observar suas ações, atitudes, comportamentos e, ainda, por meio da participação silenciosa em conversas entre os professores para a coleta de informação. O campo empírico que possibilitou este estudo compreende uma escola do campo da Rede Municipal de Rondonópolis-MT - a mesma possui dezessete professores efetivos e um professor contratado -, tendo como sujeitos seis educadores; com experiência não somente na docência, mas também na gestão, como diretor e/ou como coordenador pedagógico; com formação acadêmica e pós-graduação em nível de Especialização; com tempo de experiência na docência entre 15 e 27 anos e com o 
período de atuação na escola pesquisada entre 8 e 15 anos.

Os procedimentos metodológicos utilizados na pesquisa foram: análise documental, aplicação de questionário, transcrição dos dados e análise do questionário. A análise documental foi realizada por meio da leitura $\mathrm{e}$ interpretação de documentos como a Constituição Federal (CF), Lei $\mathrm{N}^{\circ}$ 9394/1996 - Lei de Diretrizes e Bases da Educação Nacional (LDBEN), Diretrizes Operacionais para Educação Básica das Escolas do Campo, Documento da CONAE 2010, Plano Nacional da Educação (PNE), Plano Estadual de Educação 2006/2016, Instruções Normativas do Conselho Estadual de Educação de Mato Grosso (CEE-MT).

Foram analisados, também, a Lei Orgânica do Município de Rondonópolis, documentos oficiais da Secretaria Municipal de Educação de Rondonópolis sobre estrutura e funcionamento das escolas municipais, tais como: a Lei $\mathrm{N}^{\circ}$ 128 de 06 de julho de 2012 que dispõe sobre o processo de escolha dos gestores das escolas municipais, Plano Municipal de Educação e do Projeto Político Pedagógico $^{\text {iv }}$ da escola em que a pesquisa foi desenvolvida.

Para efetuar a discussão dos dados, a opção foi pela subdivisão em três categorias: na primeira, o propósito foi descrever os dados da graduação dos entrevistados, da carreira profissional e algumas considerações conceituais referentes à educação do campo. $\mathrm{Na}$ segunda, o que foi respondido pelos professores da pesquisa com relação ao conceito de gestão democrática e de forma específica, sobre o conceito de democracia. Já na terceira e última, a discussão dos dados obtidos sobre o conceito de Projeto Político Pedagógico e a sua relação com a construção das ações e relações participativas, de modo que se buscou compreender o que pensam esses professores acerca da importância do processo de construção do Projeto Político Pedagógico como mecanismo de construção de democracia, objetivo traçado no trabalho de pesquisa.

A primeira tarefa foi a de pesquisar junto a esses sujeitos, como gostariam de ser identificados. Feito isto, quatro deles não mencionaram nada, um autorizou o uso do próprio nome e um fez a opção pelo nome de Orquídea. Frente a este impasse, optei por nomeá-los com nomes da flora que compõem o Bioma do cerrado, região onde se localiza a escola. Assim, os mesmos foram identificados como: S1 Murici, S2 - Sucupira, S3 - Jatobá, S4 Angico, S5 - Pequi e S6 - Guatambu, de 
acordo com a ordem em que as respostas estão organizadas neste trabalho.

\section{A relação entre gestão democrática e a construção da educação na perspectiva humanizadora}

Partimos do pressuposto de que, para que se constituam como instrumento de construção de ações e relações participativas e democráticas no interior das unidades escolares, não só a gestão democrática, mas também os elementos que a compõem (Processo Eleitoral, Conselho Deliberativo Escolar - CDE, Projeto Político Pedagógico) necessitam "ser provocado, vivido e apreendido por todos que pertencem ao contexto social imediato da organização escolar" (Hora, 2007), sujeitos estes, responsáveis pela organização, execução e avaliação das ações e relações pedagógicas, administrativas, políticas e culturais que dão sustentação à materialização das intencionalidades estabelecidas no Projeto Político Pedagógico de cada unidade escolar.

No conjunto de análise das respostas obtidas junto aos professores, o foco dado à participação, à transparência e à liberdade - na questão relacionada à concepção de gestão democrática - revela, de certo modo, o reconhecimento dos princípios que marcam o processo democrático. Dois professores, Murici e Sucupira compreendem gestão democrática como um modelo de gestão que "possibilita participação, transparência e democracia". Os demais, para além do foco atribuído à participação, compreendem gestão democrática como um modelo de gestão em que o estabelecimento do trabalho coletivo e o exercício de direitos e deveres se constituem como pressupostos básicos. Apenas um dos entrevistados ampliou essa noção:

Jatobá. É quando todos podem participar da gestão em busca de soluções. Gerir de forma democrática e participativa a escola significa criar condições para que todos ocupem seus lugares e seus papéis da melhor forma que for possível, em função do bem estar de si e do outro, o que significa ter presente também o grupo e o meio ambiente. Na vida escolar, o importante é o aprender a ser e o aprender a viver juntos, para o bem estar de si mesmo e do outro com qualidade.

A efetivação do processo de democratização da gestão da escola pública implica, por sua vez, por parte dos diferentes segmentos que a compõem, na compreensão da necessidade de partilha do poder, de sensibilidade para organização das atividades da escola, de levantamento das intencionalidades da comunidade escolar e, ainda, de escolhas responsáveis e coletivas. A escola, desse modo, pode ser pensada e organizada coletivamente e os 
meios para efetivação das práticas coletivas podem estar contemplados no Projeto Político Pedagógico da mesma.

A discussão em torno da construção de uma educação escolar voltada para o campo, que trabalha desde os interesses, a política e a cultura, até a economia dos diversos grupos de trabalhadores do campo, nas suas diversas formas de trabalho e de organização, pressupõe, para tanto, um conjunto de transformações no que tange à concepção de educação escolar, de escola, do papel da escola, de currículo, de gestão, de Projeto Político Pedagógico e de transformação dos educadores dessa escola, como principais agentes desses processos.

No que tange à transformação dos processos de gestão escolar, a referência é o princípio da gestão democrática que diz respeito - segundo o texto base da Educação do Campo (Kolling, Nery \& Molina, 1999) - à ampliação quantitativa e qualitativa do acesso às escolas do campo; à maior participação da população nas tomadas de decisões sobre a gestão do cotidiano escolar e sobre as propostas pedagógicas; à maior participação dos alunos na gestão do cotidiano escolar superando a mera democracia representativa, como forma de validação das decisões já tomadas anteriormente pelos gestores; e também à criação de coletivos pedagógicos, capazes de pensar e repensar esses processos de transformação e traduzi-los em ações concretas.

Entender a gestão com base em processos democráticos implica na compreensão acerca do que se entende por democracia. $\mathrm{Na}$ análise das respostas acerca da concepção de democracia, pude perceber algumas formas de entender a democracia nas falas de alguns sujeitos da pesquisa, pois, quando de suas respostas ao que concebem por gestão democrática revelam claramente um entendimento de que democracia é sistema de governo. Para Murici, democracia "É uma forma de governar, onde as decisões são tomadas junto ao povo". Quanto à resposta de Sucupira, este expressa que democracia "É um regime de governo onde as decisões são tomadas junto ao povo".

A falta de outra dimensão de democracia se apresenta na medida em que pontuam um aspecto importante que é a tomada de decisão conjunta, mas revelam uma compreensão de democracia como um sistema político ou uma forma de organização do Estado, desconsiderando, para Oliveira, a ideia de que,

A democracia pressupõe uma possibilidade de participação do conjunto dos membros da sociedade em todos os processos decisórios que dizem respeito à sua vida cotidiana, sejam eles vinculados ao poder do Estado ou aos processos interativos 
cotidianos. Assim sendo, para podermos considerar que uma determinada formação social é democrática, precisamos levar em consideração o conjunto das relações e práticas sociais desenvolvidas em todas as instâncias de inserção dos seus membros nesta mesma sociedade (2009, p. 13).

No intuito de entender os processos de democratização, foi formulada a questão: o que os professores consideram essencial para que se instale o processo de democratização da gestão escolar? Para Murici e Sucupira, o processo de democratização da gestão escolar implica na "implementação de princípios básicos da democracia como a participação e a transparência". Além destes princípios, uma visão mais ampliada do que é essencial no processo de democratização da escola é demonstrada nas argumentações abaixo:

Jatobá. O essencial nesse processo é que todos entendam o seu papel dentro da unidade de ensino, saber usar os seus direitos, bem como fazer bem os seus deveres. Ser participativo nas discussões acerca das atividades propostas pelas escolas. Ser diferente do que ocorre na política partidária ou, mesmo, na vida cotidiana da sociedade.

Angico. Depende da união da comunidade escolar. É quando a grande maioria das decisões seja tomada através de estudos coletivos sobre o assunto.

Pequi. Evitar direção vitalícia para não criarmos ditadores dentro das escolas. Deve respeitar, também, o desejo da maioria, permitindo que direitos e deveres sejam resguardados.

Guatambu. É a participação de todos envolvidos na gestão escolar, onde todos participam, sugere e tem suas opiniões discutidas, avaliadas e acatadas de acordo com as necessidades apresentadas.

Mesmo pensando nas formas de consolidação dos processos de democratização da gestão escolar, Pequi evidencia uma discussão polêmica, mas presente nas escolas municipais de Rondonópolis ao argumentar que é essencial no processo de democratização da escola "Evitar direção vitalícia para não criarmos ditadores dentro das escolas". A resposta dada indica um quadro complicado e conflitante, na medida em que demonstra que as relações verticais, de mando e comando, de subordinação e de personificação ainda fazem parte dessa instituição. Nesse caso, o interessante é o caráter revelador da situação de resistência quando o poder se concentra na direção da escola, melhor dizendo, quando há insistência na continuidade de um modelo autoritário de gestão.

$\mathrm{Na}$ atual conjuntura, uma preocupação se apresenta em torno do fato de que o processo de escolha do dirigente da escola pela via eleitoral tem sido alvo de grande controvérsia, marcado, portanto, por avanços e retrocessos. Avanços no sentido de que foi superada a forma 
"tradicional" de escolha do gestor escolar, que se configurava pela ótica políticopartidária, independente das expectativas da comunidade escolar. Retrocessos, na medida em que o processo de escolha pela via do voto tem sido entendido, de modo geral, como um fim em si mesmo, não sendo compreendido como instrumento que proporcione, de fato, $\mathrm{o}$ direito à participação. Assim concebido, este processo perde, efetivamente, o seu sentido por ser desvinculado do fator dito como responsável pela implantação da própria gestão democrática no ensino público, que é a busca da qualidade social do processo educativo.

O ser humano se apresenta no mundo com um potencial que o constitui como humano. Esse potencial, por sua vez, vai concretizando-se ao longo da vida mediante as relações estabelecidas, ou ainda, segundo Severino (1998), com as diferentes práticas sociais: produtiva, social e simbólica. Essas relações que constituem a condição do ser humano implicam, por sua vez, na criação de instituições que, na perspectiva coletiva, possam contribuir de forma significativa, como por exemplo, a educação formal, por meio da organização da escola e das relações pedagógicas ali estabelecidas. Para que a educação formal contribua para com a concretização do ser humano como humano é salutar entender que, o homem tem,

um jeito especificamente humano de realizar a sua humanidade. Ele é, de fato, um ser em permanente construção, que vai se fazendo no tempo pela mediação de sua prática, de sua ação histórica. É assim um ser que vai se criando no espaço social e no tempo histórico. Não é apenas uma realidade pronta e acabada, mas um sujeito que vai construindo aos poucos sua própria realidade. Ela não é dada sequer como um programa rígido tal como ocorre no plano natural do código genético dos seres vivos (Severino, 1998, p. 83).

Educação escolar é aqui entendida como um projeto educacional intencional que estabelece um entrecruzamento com o projeto histórico e social, e que, em função deste entrecruzamento, são estabelecidas as intencionalidades, que têm orientado a organização da escola no cumprimento de sua função social que, na argumentação de Severino (1998), se constitui como um meio de preparação do indivíduo para a sua inserção na prática produtiva (trabalho), na prática social (sociabilidade) e na prática simbólica (cultural).

Quando se trata, especificamente, dos processos formativos nas instituições de ensino e pesquisa, se trata na realidade da educação no âmbito da escola, enquanto espaço privilegiado de realização da educação sistematizada que deve se dar não só pela ação dialógica, mas também pela conformação da consciência crítica, 
que ainda carece de um trabalho de formação democrática, a qual, “ao proporcionar valores e conhecimentos, possibilita uma formação para o exercício da cidadania" (Hora, 2007, p. 32). Discutir, no entanto, gestão democrática no interior da educação pressupõe entendermos que,

No Brasil duas tendências opostas têm predominado: a centralização e a descentralização. Entretanto, a tendência à centralização sempre foi predominante, mesmo em períodos quando o discurso oposto sempre esteve presente. O movimento de descentralização não é um fato isolado, pelo contrário, é um dos elementos de uma reforma mais geral das estruturas e dos procedimentos dos governos nacionais (Lima, 2007, p. 59).

Essa centralização do comando e do poder de decisão, que mesmo com a gestão democrática continua forte, tem se explicado nas esferas administrativas centrais, nos últimos tempos, pela dependência estabelecida entre o governo central e os governos estaduais com os grupos econômicos internos, mas, sobretudo, com as "poderosas" forças externas, em especial, com o Banco Mundial e o Fundo Monetário Internacional-FMI, decorrendo daí o pouco, ou quase nulo, poder que o setor da educação ocupa nos espaços em que as tomadas de decisões mais gerais da educação acontecem. O Banco Mundial tem exercido um papel fundamental no que se diz respeito à "determinação" das políticas educacionais no contexto brasileiro.

Ao analisar as influências externas no desenvolvimento de políticas educativas, sobre os países em desenvolvimento, em especial as do Banco Mundial, Verger e Bonal evidenciam como elas ocorrem:

El Banco Mundial no cuenta con un mandato oficial en educación debido a que la UNESCO es formalmente la institución del sistema de Naciones Unidas especializada en educación. No obstante, paradójicamente, el Banco se ha convertido en una de las organizaciones internacionales más influyentes en ámbito de $\mathrm{La}$ educación para el desarrollo “..." poderia considerar-se que el Banco tiene un amplo e implícito mandato en educación. Debido al alcance territorial del Banco Mundial, sus métodos de estudios y sus recomendaciones deben ser aplicables necesariamente a diferentes contextos sociales y sistemas educativos (2011, p. 919).

Desta forma, ao pensarmos em um processo de democratização da gestão escolar, um dos pontos de partida é justamente o de se ter a clareza do que seja gestão e de como se caracteriza a gestão democrática, uma vez que concomitante à construção deste modelo de gestão tem se dado uma nova forma de organização da escola. Todavia, a implementação de um modelo de gestão, calcado em princípios democráticos, no interior das instituições 
educacionais, não tem demonstrado ser uma tarefa fácil.

Instaurar processos democráticos na escola exige, portanto, a clareza do que significa efetivamente $\mathrm{o}$ processo de democratização da escola para cada um de seus segmentos, especialmente do significado da democracia. De acordo com Hora (2007), é importante

Compreender o processo democrático e assumir práticas nessa direção pressupõe a discussão do conceito de democracia, pois seu exercício envolve uma série de valores que nem sempre são partilhados pelos que a defendem, dificultando sua definição quando tratamos de sua aplicação na escola (p. 48).

Assim, é fundamental ter a clareza de que democracia não diz respeito tão somente a uma forma de governo, democracia é modo de vida. É a forma como as pessoas agem e estabelecem relações, o que exige, para o seu exercício, um conjunto de condições que devem ser adotadas pelos sujeitos que compõem uma instituição, a fim de concretizar o princípio fundamental da participação. Segundo a autora, estas condições dependem de se assegurar alguns pontos, tais como:

O livre fluxo das ideias, permitindo às pessoas o acesso à informação; a fé na capacidade individual e coletiva; uso da reflexão e da análise crítica para avaliar ideias, problemas e políticas; a preocupação com o bem-estar dos outros e com o bem comum; a preocupação com a dignidade e os direitos das pessoas; a compreensão de que a democracia não é tanto um "ideal" a ser buscado, como um conjunto de valores "idealizados" que devemos viver e que devem regular nossa vida enquanto nação; a compreensão acerca da importância da organização de instituições sociais para promover e ampliar o modo de vida democrático (Hora, 2007, p. 52).

Os instrumentos de gestão democrática organizam-se em instâncias de deliberação direta ou indireta e propiciam espaços de participação e de criação da identidade escolar. Também é fundamental que o professor esteja integrado à comunidade ou ao movimento social da qual ela faz parte, isto porque o movimento organizado do campo pode ser um excelente aliado na construção democrática da prática social da educação e, além disso, porque a escola isolada da realidade da comunidade é só um prédio. Porém, ela vista como parte dessa realidade, com seus problemas e perspectivas, é uma mola propulsora para o seu desenvolvimento.

Esse processo, por sua vez, depende da tomada de consciência de que a gestão democrática só se constitui quando entendida como um projeto coletivo, como um projeto cuja compreensão seja a de que o desenvolvimento dialético de qualquer sistema social, intrinsecamente trabalhado por forças contraditórias, não consegue se viabilizar de forma mecânica e linear, e 
que, nesse sentido, embora o Projeto Político Pedagógico não se constitua como um único mecanismo que contribui com a construção da democracia, pode ser considerado como o passo mais importante na organização da estrutura e do funcionamento da escola: na construção de ações e relações participativas e democráticas.

O processo de elaboração do Projeto Político Pedagógico como instrumento fundante na construção de ações e relações democráticas no interior da escola

Democratização da escola pressupõe relações interpessoais, como enfatiza Oliveira (2009), ou seja, pressupõe a revalorização das relações de solidariedade, de cooperação, de reconhecimento do caráter coletivo dos processos de tessitura de conhecimentos e, ainda, de construção de identidade, o que pressupõe a democratização não só dos aspectos administrativos, mas também da ação pedagógica. Para que essa revalorização ocorra, requerem-se, diga-se de passagem, ações concretas em termos de redefinição das intencionalidades da escola, objetivos, proposta curricular, política de formação do quadro de profissionais da escola, entre outros, sendo essa uma luta árdua e longa, em que a sua materialização depende de ações coletivas.
A democratização da educação, nesse sentido, não se limita ao acesso à escola. O acesso é, certamente, a porta inicial para o processo de democratização, mas torna-se necessário, também, garantir que todos que ingressam na escola tenham condições para nela permanecerem, com sucesso. Assim, a democratização da educação faz-se com acesso e permanência de todos no processo educativo, dentro do qual o sucesso escolar é reflexo de sua qualidade.

É fundamental ter claro, todavia, que somente essas três características (acesso, permanência e sucesso) ainda não completam o sentido amplo da democratização da educação, pois a última faceta de tal democratização é a necessidade de que o processo educativo seja um espaço para o exercício democrático, estabelecido, sobremaneira, no processo de construção de ações e relações, quando estas são realizadas coletivamente. Sabe-se, pois, que é na garantia da participação que a escola pode assegurar a descentralização das tomadas de decisão como fator essencial para conquistar a sua democratização.

É imprescindível, para tanto, considerar a importância da participação da comunidade escolar como forma de ação inclusiva, dinâmica e participativa no processo de construção e reconstrução do 
Projeto Político Pedagógico. Por conseguinte, cabe à equipe gestora da escola, em articulação com o Conselho Deliberativo Escolar, a criação de espaços de participação da comunidade no cotidiano escolar, visto que o sucesso de uma instituição se dá de acordo com o planejamento, execução e avaliação de um projeto elaborado criteriosamente. Esses são passos importantes para a democratização da gestão, entendendo a democracia como Carvalho (2006),

Democracia se configura pela participação que traz como exigência ação de tomar parte de... No caso da escola, requer que a democracia seja constituída na dimensão da ação direta e não representativa, caso contrário, ela perde a razão de ser “..." ela não pode ser delegada para outro, pelo contrário, o sujeito tem que exercer a sua função de legislar, executar e avaliar o processo educativo (p. 182).

A efetivação desse processo de democratização da gestão da escola pública implica, portanto, em partilha do poder, em sensibilidade para conduzir a escola a partir das demandas da comunidade escolar, e na tomada de decisões e escolhas responsáveis e coletivas. Em se tratando da escola do campo, acredito que a sua democratização se viabilizará a partir do processo de construção coletiva de seu Projeto Político Pedagógico.
Construir uma escola do campo significa pensar e fazer a escola desde o projeto educativo dos sujeitos do campo, trazer para dentro da escola as matrizes pedagógicas ligadas às práticas sociais, combinar estudo com trabalho, com cultura, com organização coletiva e com postura de transformação do mundo, e, ainda, prestar atenção às tarefas específicas do tempo e do espaço da escola. Pensar a escola desde o seu lugar e seus sujeitos, dialogando sempre com a realidade mais ampla e com as grandes questões da educação e da humanidade.

Os novos cenários em que a gestão democrática da escola pública está inserida precisam ser compreendidos como um processo amplo da emancipação humana, sendo que esse processo deve ser considerado como uma exigência para se alcance a autonomia e a construção de processos de democratização da gestão escolar. É nesse horizonte que o processo de construção do Projeto Político Pedagógico se configura como uma das possibilidades de democratização da gestão escolar das escolas do campo.

Partindo dessa constatação, optei por averiguar, junto aos sujeitos, uma questão que considero de fundamental importância para a compreensão do nosso objeto de estudo que é a compreensão que os professores têm do que seja o Projeto 
Político Pedagógico da escola. Ao serem questionados sobre o que é o Projeto Político Pedagógico e para que serve na escola, obtivemos as seguintes respostas:

Murici. É o norteador de todo o processo educacional, serve para direcionar os objetivos que se pretendem.

Sucupira. É o projeto no qual se estabelece o norte do processo educacional, onde direciona todos os objetivos.

Jatobá. $O$ Projeto Político Pedagógico busca um rumo, uma direção, nele reside a possibilidade da efetivação da intencionalidade da escola. É o fruto da interação entre os objetivos e prioridades estabelecidas pela coletividade, que estabelece através da reflexão, as ações necessárias às escolas de cumprirem seus objetivos, suas ações. É um trabalho que exige comprometimento de todos os envolvidos no processo educativo: professores, equipe técnica, alunos, seus pais e a comunidade como um todo. Trata-se, portanto, da conquista coletiva de um espaço para o exercício da autonomia, servindo assim a toda comunidade escolar.

Angico. É o documento norteador das ações dentro da escola. Serve para regulamentar, direcionar e legitimar as ações e obrigações dentro da unidade escolar.

Pequi. Não respondeu.

Guatambu. É um projeto organizado por todos os setores da escola. Visa organizar e determinar as diretrizes organizacionais do trabalho desenvolvido pelos profissionais da escola.

As respostas demonstram, de certo modo, posicionamentos similares com relação à ideia de que o projeto deve ser construído na perspectiva coletiva. De um lado, remetem à ideia de projeto como estrutura formal e burocrática em que são organizadas e regulamentadas as ações cotidianas da instituição escolar e, por outro lado, o compreendem como espaço em que coletivamente se estabelecem e cumprem os objetivos educacionais, que respondem questões atinentes ao tipo de homem que se quer formar e, em função disso, o tipo de escola que se quer construir.

Percebe-se, com as respostas obtidas, uma compreensão da necessidade de construção do Projeto Político Pedagógico em uma perspectiva coletiva. Penso que um dos grandes desafios da sociedade, sobretudo da escola, é formar sujeitos com a consciência e o compromisso da coletividade. Entendida nessa direção, a ideia de coletividade deve ser considerada como sustentação da construção da escola numa ou noutra direção. Isso significa que, na escola, essa ideia pode resultar em esforços para que surjam estruturas organizacionais compatíveis com as expectativas de vida pretendidas pelos sujeitos que dela participam.

$$
\text { De acordo com Paro (1997), a }
$$
participação da comunidade no cotidiano da escola depara-se com inúmeros obstáculos para que possa se concretizar efetivamente na sua prática e um dos empecilhos para que ela se efetive é 
justamente o fato da convicção dos sujeitos sobre a relevância da sua participação, pois a baixa escolaridade é motivo para se sentirem menosprezados e incapazes de contribuir com o processo de ensino da escola. Para Garske (1998),

Essa participação, como todo processo democrático, é também um caminho que se faz ao caminhar. Daí a importância de se ter o PPP como instrumento que dá direção a essa caminhada. E é justamente esse mais um dos grandes limites da escola: a dificuldade de buscar formas de participação da comunidade na escola, e o que é pior, a falta de compreensão de que o projeto poderia se estabelecer como $\mathrm{o}$ instrumento que daria condições reais e efetivas de participação da comunidade nas tomadas de decisão e na execução do seu projeto (p. 108).

A ampliação dos processos democráticos e a participação de todos os setores da comunidade escolar constituem um desafio para a gestão administrativa comprometida com a descentralização e a socialização do poder. Os professores não são seres iluminados e nem os únicos capazes de contribuir com a organização e intencionalidades da escola. A participação de todos os sujeitos que compõem a comunidade escolar na elaboração e execução do Projeto Político Pedagógico contribui para o desenvolvimento da autonomia e das práticas democratizantes no interior da escola, pois a participação pode resgatar o sentido da educação pública em termos da organização e do poder de tomar as decisões na ação educativa, além de abrir canais que favoreçam o exercício da democracia na escola, pois a intencionalidade da escola pública exige é que seja democrática.

A democracia não se limita apenas ao processo eleitoral, a democracia se aprende com a prática da participação, sugere convivência e aprendizado nas tomadas de decisão com igualdade de direitos; não se trata apenas de marcar presença nas reuniões para se legitimar as decisões, trata-se de uma participação responsável e comprometida, em que os sujeitos - mesmo analfabetos - são autônomos capazes de conduzir uma organização da prática pedagógica escolar autônoma e democrática, na qual o sujeito que transforma é também responsável por sua transformação.

Nas respostas obtidas junto aos sujeitos da pesquisa percebe-se que, dentre as ações previstas pelo Projeto Político Pedagógico, existem aquelas que buscam assegurar o processo de interação entre escola e comunidade. O que se verifica, por meio das respostas, é o reconhecimento que os profissionais da educação têm da importância da articulação entre escola e comunidade. No entanto, as ações previstas no Projeto Político Pedagógico da escola 
pesquisada, conforme as respostas obtidas, não consideram o potencial dessa articulação na construção da gestão democrática e na construção de uma educação escolar de qualidade social, na medida em que essa comunidade não assume o papel que poderia e deveria assegurar uma atuação mais ativa e efetiva, de caráter, portanto, consultivo, decisivo, avaliativo e educativo, como elementos essenciais em um processo que se quer democrático.

Não se pretende fazer aqui a apologia de que "na escola tudo pode", mas apontar que, mesmo diante de todas as dificuldades a serem enfrentadas no atual contexto, as escolas têm condições, na pretensão de construção de uma gestão democrática, de encontrar caminhos que garantam um envolvimento mais ativo e afetivo da comunidade no seu interior. Para tanto, torna-se necessária a compreensão, pelos segmentos da escola, de que os princípios da exclusão, da seletividade e do autoritarismo, ainda presentes nessa instituição, devem ser substituídos pelos princípios da inclusão, do respeito às diferenças, da descentralização do poder de decisão, como bases para construção de uma escola humanizadora e comprometida com um projeto político social mais amplo.
Para Carvalho, ao discorrer sobre as finalidades da construção do Projeto Político Pedagógico, nos esclarece que:

A questão nuclear que deve ser destacada é que se não há participação, decisão coletiva, não há democracia, assim como não há democracia sem organização. Porém, para que a cultura democrática prospere na escola, faz-se necessário que a gestão seja democrática. É evidente que não se constrói democracia sem conflito. O exercício democrático na sociedade, também na escola é permeado por interesses divergentes (2006, p. 183).

Nesse sentido, urge o delineamento de um Projeto Político Pedagógico alicerçado nos princípios democráticos, em novos princípios educativos e em um projeto histórico de sociedade, a sociedade igualitária e solidária. O que será possível por meio do trabalho pedagógico, que é o modo de organização que a escola assume na tarefa de pensar e produzir as relações de saber entre sujeitos e o mundo concreto. Construir uma escola do campo nessa perspectiva significa, segundo Caldart (2002),

Pensar e fazer a escola desde o projeto educativo dos sujeitos do campo, tendo o cuidado de não projetar para ela o que a sua materialidade própria não permite; trazer para dentro da escola as matrizes pedagógicas ligadas às práticas sociais; combinar estudo com trabalho, com cultura, com organização coletiva, com postura de transformar o mundo “...” pensar a 
escola desde o seu lugar e os seus sujeitos, dialogando sempre com a realidade mais ampla e com as grandes questões da educação, da humanidade e da educação do campo (p. 35).

É nessa direção que se constitui a possibilidade de construção de um Projeto Político Pedagógico que contemple as características da educação do campo.

Foi questionado aos sujeitos desta pesquisa se o Projeto Político Pedagógico da escola contempla as peculiaridades da Educação do Campo e da comunidade da qual a escola faz parte, porém, quando se refletiu acerca das respostas dadas, foi possível perceber que elas evidenciaram que parte dos sujeitos da pesquisa não se atentou a duas questões básicas de um modelo de educação que se propõe na Resolução 01/2002 para as escolas do campo: primeiro que um projeto dessa natureza deve contemplar as características culturais dos povos do campo. Aliás, esta é a principal característica da política de educação do campo. Segundo é o desconhecimento do que é peculiar nessa política, que está posto, atendo-se apenas à adequação do calendário com relação aos eventos da comunidade.

Não ficou evidenciado que a valorização dos sujeitos do campo, assim como a utilização da proposta de educação do campo, se configura como respeito às peculiaridades da educação do campo. Caso se compare as respostas dadas a essa pergunta com as respostas dadas pelos sujeitos quando os mesmos foram questionados se a escola do campo deve organizar o seu processo de ensino de acordo com os anseios da comunidade e o porquê, observa-se que parece que uma proposta de Educação do Campo ainda se encontra em nível de ideário apenas. Ao se refletir sobre as respostas dadas pelos sujeitos para essas duas questões, concordamos com Carvalho (2006),

O fato real é que no contexto da escola realiza-se muita atividade, mas aquilo que é pensado e estabelecido no Projeto Político Pedagógico acaba não sendo concretizado, tampouco servindo de referência para definição da ação pedagógica. Isto porque o Projeto Político Pedagógico está sendo sufocado pelo projeto de desenvolvimento escolar que tem um caráter mais gerencial de determinar tarefas para ser executado pelos professores (p. 184).

Nessa busca de relação entre a escola e a comunidade, Machado (2003), evidencia que é a concepção de campo que se deve ter como referência ao tratar de educação do campo, considerando o protagonismo das crianças e jovens, educadoras e educadores camponeses na luta por uma educação que corresponda aos seus ideais e que na elaboração de um projeto pedagógico para a escola do campo deve-se, primeiramente, ter presente a 
concepção de educação do campo, suas finalidades e princípios básicos, como forma de caracterizar que espaço de atuação é esse, bem como os mecanismos de ação que melhor se aplicam a esse contexto. Para ela,

É preciso fazer uma educação que assuma a identidade do povo do campo, respeitando seu modo de vida, sua dinâmica social e acolhendo seus saberes e experiências no processo pedagógico. E isso implica na definição de um projeto pedagógico que objetive a formação da criança e jovem na perspectiva do desenvolvimento sustentável e coletivo do campo (Machado, 2003, p. 197).

De acordo com a autora, a construção de um projeto nessa perspectiva requer uma relação intrínseca entre as necessidades apresentadas, o conteúdo do projeto e as suas condições de implementação. Fundamenta-se no princípio de participação dos representantes dos diversos segmentos da escola durante o seu processo de construção e de execução, pois o mesmo trata do levantamento das expectativas e necessidades da escola na visão daqueles que dela participam, assim, é possível contemplar os anseios do homem do campo.

Porém essa participação só será efetiva se os membros de cada segmento se sentirem importantes e necessários nesse processo. Os membros precisam sentir-se úteis e competentes para que tomem gosto pela participação, para se engajarem na luta, nas discussões e deliberações nos diversos assuntos realizados sobre $\mathrm{O}$ cotidiano da escola.

Um ponto relevante no envolvimento da construção e execução de um projeto de natureza política e pedagógica visando à construção de um novo modelo de escola é a compreensão de que não se pode pensar em transformação da escola sem pensar na questão das finalidades educativas e no processo de avaliação do projeto de formação humana que fundamenta estas finalidades. Esta concepção decorre do fato de que qualquer prática educativa que se fundamenta em uma concepção de ser humano, em uma visão de mundo e em um modo de pensar os processos de humanização e formação do ser humano, precisa entender, basicamente que essa é uma ação intencional e sistemática, o que pressupõe revisão do como está sendo desenvolvida e dos resultados alcançados.

Tanto o projeto de educação do campo quanto à formação dos sujeitos que ali vivem, implicam no que está posto como intencionalidade do projeto da escola, que os sujeitos responsáveis pela construção, execução e avaliação deste projeto percebam criticamente as escolhas feitas e que sejam capazes de formular 
alternativas que favoreçam o processo de transformação social, ou seja, formular e executar esse projeto de educação integrado a um projeto de transformação liderado pela classe trabalhadora. Esse processo pode ocorrer por meio de estratégias pedagógicas que transcendam os muros da escola como forma de superar a fragmentação do conhecimento, vigente na maioria dos processos de ensino/aprendizagem.

Neste horizonte alguns princípios precisam ser assegurados, tais como: reciprocidade, que elimina a exploração; solidariedade, que supera a opressão; e autonomia, que atenua a dependência, uma vez que não podemos ser totalmente independentes, pois temos princípios e normas que, mesmo em um modo de vida democrático, precisam ser respeitados. A busca da gestão democrática inclui, necessariamente, a ampla participação dos representantes dos diferentes segmentos da escola nas decisões/ações administrativopedagógicas ali desenvolvidas. Para Veiga (2002), fica claro que:

A gestão democrática, no interior da escola, não é um princípio fácil de ser consolidado, pois se trata da participação crítica na construção do Projeto Político Pedagógico e na sua gestão. É preciso ter consciência de que a dominação no interior da escola efetiva-se por meio das relações de poder que se expressam nas práticas autoritárias e conservadoras dos diferentes profissionais, distribuídos hierarquicamente, bem como por meio das formas de controle existentes no interior da organização escolar. Como resultante dessa organização, a escola pode ser descaracterizada como instituição histórica e socialmente determinada, instância privilegiada da produção e da apropriação do saber (p. 72).

A democratização da gestão, nesse sentido, ocorrerá com a descentralização de poder, a participação de todos os segmentos da escola e da comunidade no processo de construção e/ou de reestruturação do Projeto Político Pedagógico da escola e a eleição para os cargos de gestão escolar, abrindo-se à possibilidade da participação da sociedade civil no debate da política de educação democrática, idealizando e propondo que a escola se torne um espaço de relações democráticas ao romper com a cultura da hierarquização, subordinação, alienação e clientelismo. Desta forma, a gestão democrática fortalece e abre espaços para que toda a comunidade escolar passe a discutir a gestão da escola, na perspectiva de construir uma estrutura democrática de gestão e, em decorrência disso, um ensino de qualidade.

Este processo de mudança demanda, por sua vez, que a instituição escolar deixe de ser um lugar restrito aos professores e abra espaço para a comunidade participar 
nas tomadas de decisões no interior da escola com a finalidade de contribuir para a melhoria da qualidade do ensino ofertado à comunidade da qual ela faz parte. Neste sentido, democratizar a gestão na escola pública é, também, compreender a função social a ser cumprida por esta escola, comprometida com a transformação e em busca da construção de uma sociedade mais justa, humanitária e menos excludente.

Para que a escola prime e institua um caráter democrático é necessário o desenvolvimento de um conjunto de práticas e atividades que favoreçam e estimule a participação ativa da comunidade. Essa participação deve se constituir na dimensão da construção do projeto educativo da escola como forma de se tomar parte da constituição do caminho que a escola deve trilhar. E mais, esse trabalho coletivo na escola precisa ter como eixo a compreensão de que cada sujeito é constituído em um determinado contexto histórico e social e que a educação é condição indispensável para a realização histórica do ser humano.

Não podemos nos esquecer de que a democracia, nesse sentido, não é dada previamente, mas se constitui enquanto uma conquista árdua que necessita de um envolvimento de todos. A democracia é uma construção, portanto, uma aprendizagem permanente. $\mathrm{O}$ fato real é que não deve existir projeto democrático na escola que seja pensado e organizado de forma unilateral, tampouco por outro agente externo ao processo educativo do cotidiano escolar. $\mathrm{Na}$ verdade, as respostas dos sujeitos e as discussões realizadas pelos estudiosos do assunto, demonstram uma compreensão de que um projeto democrático é construído por sujeitos, demandando assim, a possibilidade de participação de toda comunidade escolar professores, funcionários, alunos e comunidade local - em todos os processos decisórios que dizem respeito ao cotidiano da escola.

Nesse horizonte, para podermos considerar que, para entender se uma escola se configura como democrática ou não, precisamos analisar o conjunto das ações e relações ali vivenciadas, sendo o projeto político pedagógico um elemento da gestão democrática que foi constituído para organizar estas ações e relações numa perspectiva participativa e democrática. Pois, o projeto político pedagógico pode ser entendido como a própria organização do trabalho pedagógico da escola e a sua construção deve ter como parâmetro princípios democráticos, entendendo, claro, que a escola é concebida como espaço social marcado pela manifestação de práticas contraditórias, que apontam 
para a luta e/ou acomodação de todos os envolvidos na organização do trabalho pedagógico.

A possibilidade de implementação de processos democráticos diante do universo da escola, marcado por manifestação de práticas contraditórias, é um desafio que depende da atenção dada à premissa de que as dificuldades e os desafios que o Brasil tem enfrentado na prática da educação e na sua gestão, sobretudo no momento atual, podem ser compreendidos quando nosso olhar considera o contexto das forças econômicas, políticas e culturais no interior da nação e no âmbito das suas relações de interdependência internacional. A forma como a escola tem sido entendida e organizada tem uma relação direta com este contexto.

\section{Considerações finais}

$\mathrm{O}$ que se procurou, ao longo deste artigo, foi discutir a possibilidade de implementação de processos democráticos no universo da escola, marcado por manifestação de práticas contraditórias. Este é um desafio que depende da atenção dada à educação e a sua gestão. Para que a escola prime e institua um caráter democrático é necessário o desenvolvimento de um conjunto de práticas e atividades que favoreçam e estimulem a participação ativa da comunidade. Essa participação deve se constituir na dimensão da construção do projeto educativo da escola como forma de se tomar parte da elaboração do caminho que a escola deve trilhar. E mais, esse trabalho coletivo na escola precisa ter como eixo a compreensão de que cada sujeito é constituído em um determinado contexto histórico e social e que a educação é condição indispensável para a realização histórica da pessoa.

Não podemos nos esquecer de que a democracia, nesse sentido, não é dada previamente, ao contrário, se constitui como uma conquista árdua que necessita de um envolvimento de todos. A democracia é uma construção, portanto, uma aprendizagem permanente. $\mathrm{O}$ fato real é que não existe projeto democrático na escola pensado e organizado de forma unilateral, tampouco por outro agente externo ao processo educativo do cotidiano escolar. $\mathrm{Na}$ verdade, as respostas dos sujeitos e as discussões realizadas pelos estudiosos do assunto demonstram uma compreensão de que um projeto democrático é construído por sujeitos, demandando, assim, a possibilidade de participação de toda comunidade escolar professores, funcionários, alunos e comunidade local - em todos os processos decisórios que dizem respeito ao cotidiano da escola. 
Nesse horizonte, para se entender se uma escola se configura como democrática ou não, precisa-se analisar o conjunto das ações e relações ali desenvolvidas. Assim, devido ao fato de que a construção do Projeto Político Pedagógico é um instrumento da gestão democrática, ele pode ser constituído para organizar, justamente, essas ações e relações em uma perspectiva participativa e democrática.

Tem-se, então, que o Projeto Político Pedagógico pode ser entendido como a própria organização do trabalho pedagógico da escola e a sua construção deve ter como parâmetro princípios democráticos, entendendo, claro, que a escola é concebida como espaço social marcado pela manifestação de práticas contraditórias, que apontam para a luta e/ou acomodação de todos os envolvidos na organização do trabalho pedagógico.

Diante das respostas dos sujeitos da pesquisa, posso dizer que é possível inferir que a forma de participação dos sujeitos nessa unidade escolar ainda não está consolidada como processo amplo e efetivo de participação, como algo próximo ao desejável. E a elaboração do Projeto Político Pedagógico se estabelece, ainda, como procedimento voltado para o cumprimento de formalidade técnica e das exigências legais. Nele, quando muito, se insere alguma ação da comunidade como forma de democratização da gestão. $\mathrm{Na}$ verdade, os processos de participação e de democratização da gestão escolar se resumem expressivamente ao processo eleitoral, tendo a eleição para a escolha do gestor como a forma alternativa de democratização da gestão.

É importante ressaltar, ainda, que a participação da comunidade escolar no cotidiano da escola depara-se com inúmeros obstáculos que impedem que se concretize efetivamente a sua prática, principalmente pela falta da convicção dos sujeitos sobre a relevância da sua participação, por obstáculos como concentração da ação, do poder, da tomada de decisões e pela falta de abertura para discussões. Porém, é importante ter a clareza de que nem uma cultura, nem práticas escolares e costumes se mudam de um dia para o outro ou apenas por vontade de alguém, mas com ações estabelecidas no cotidiano.

\section{Referências}

Brasil. (2002). Diretrizes operacionais para a educação básica do campo. (Resolução CNE/CEB 1, de 03 de abril de 2002). Brasília: Conselho Nacional de Educação - Câmara de Educação Básica 134.

Constituição da República Federativa do Brasil de 1988. (2007). Rio de Janeiro, DP \& A Editora. 
Caldart, R. S. (2002). Por uma educação do campo: traços de uma identidade em construção. In Kolling, E. J., Cerioli, P. L., \& Caldart, R. S. (Orgs.), Educação do campo: identidade e políticas públicas (pp. 25-36). Brasília, DF: NEAD.

Carvalho, A. L. (2006). A formação centrada na escola: a ponte edificadora do projeto político pedagógico. In Monteiro, F. M. A., \& Muller, M. L. R. (Orgs.). Profissionais da educação: políticas, formação e pesquisa (pp. 183-196). Cuiabá, MT: EdUFMT.

Escola Municipal Rural de Ensino Fundamental Fazenda Carimã (2013). Projeto Político Pedagógico. Rondonópolis, MT.

Garske, L. M. N. (1998). Um novo fazer administrativo e pedagógico no processo de democratização da escola pública (Dissertação de Mestrado). Universidade Federal de Mato Grosso, Cuiabá.

Hora, D. L. (2007). Gestão educacional democrática. Campinas, SP: Editora Alínea.

Koling, E. J., Nery, I. I. J., \& Molina, M. C. (Orgs.). (1999). Por uma educação básica do campo. Brasília, DF: MST, $\mathrm{UnB} / \mathrm{CNBB} / \mathrm{UNICEF} / \mathrm{UNESCO}$.

Lima, M. R. C. (2007). Paulo Freire e a administração escolar. Brasília, DF: Liber Livros Editora.

Machado, I. F. (2003). A organização do trabalho pedagógico em uma escola do MST e a perspectiva de formação omnilateral (Tese de Doutorado). Universidade Estadual de Campinas, Campinas.

Oliveira, I. B. (2009). Democracia no cotidiano da escola. Petrópolis, RJ: DP \& A Editora.
Paro, V. H. (1997). Administração escolar e qualidade do ensino: o que os pais ou responsáveis têm a ver com isso? In Simpósio Brasileiro de Política $e$ Administração da Educação (pp. 303-314). Porto Alegre, RS.

Severino, A. J. (1998). O projeto políticopedagógico: uma saída para a escola. Para onde vai a escola? Revista de Educação da AEC, 27(107), 81-91.

Veiga, I. P. A. (2002). Projeto políticopedagógico da escola: uma construção coletiva. In Veiga, I. P. A. (Org.). Projeto político-pedagógico: uma construção possível. Campinas, SP: Papirus.

Verger, A., \& Bonal, X. (2011). La estrategia educativa 2020 o las limitaciones del Banco Mundial para promover el "aprendizaje para todos". Educação \& Sociedade, 32(117), 911-932.

\footnotetext{
${ }^{\mathrm{i}} \mathrm{O}$ estudo conta com o apoio do Conselho Nacional de Desenvolvimento Científico e Tecnológico (CNPq), por meio do Edital Universal (2014-2017).

ii Conflitos de Interesse: Edson Caetano é membro do Conselho Editorial Nacional da Revista Brasileira de Educação do Campo e não participou do processo de avaliação do artigo.

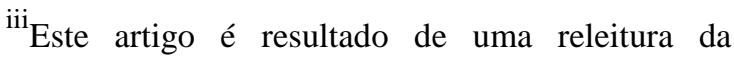
dissertação de mestrado defendida na UFMT/CUR em 2014.

${ }^{\text {iv }} \mathrm{O}$ Projeto Político Pedagógico da Escola Municipal de Ensino Fundamental Rural Fazenda Carimã foi elaborado em 2013.
}

Recebido em: 20/06/2017 Aprovado em: 08/08/2017 Publicado em: 11/09/2017 
Como citar este artigo / How to cite this article / Como citar este artículo:

APA:

Caetano, E., \& Silva, I, R. (2017). O significado do Projeto Político Pedagógico na construção de ações e relações participativas na educação do campo. Rev. Bras. Educ. Camp., 2(2), 607-631. DOI: http://dx.doi.org/10.20873/uft.2525-

$\underline{4863.2017 \mathrm{v} 2 \mathrm{n} 2 \mathrm{p} 607}$

ABNT:

CAETANO, E.; SILVA, I, R. O significado do Projeto Político Pedagógico na construção de ações e relações participativas na educação do campo. Rev. Bras. Educ. Camp., Tocantinópolis, v. 2, n. 2, p. 607-631, 2017.2 DOI: http://dx.doi.org/10.20873/uft.25254863.2017v2n2p607

\section{ORCID}

\section{Edson Caetano}

(iD) http://orcid.org/0000-0001-9906-0692

Iorim Rodrigues da Silva

(iD) http://orcid.org/0000-0002-8675-5759 